\title{
Influência dos fenômenos ENOS na bacia hidrográfica do Atlântico Sudeste
}

\author{
Leda Veiga Calderon Almeida ${ }^{(a)}$, Jonas Teixeira Nery ${ }^{(b)}$ \\ (a) UNESP/Ourinhos, Universidade Estadual Paulista, heyleda@me.com; \\ (b) UNESP/Ourinhos, Universidade Estadual Paulista, jonas@ourinhos.unesp.br;
}

\section{Eixo Climatologia em diferentes níveis escalares:mudanças e variabilidade}

\begin{abstract}
Resumo
O presente estudo é uma análise dos fenômenos El Niño - Oscilação Sul (ENOS), associado as chuvas na área de estudo. Esse evento é caracterizado por anomalias positivas (El Niño) ou negativas (La Niña) e sua influência na qual afetam a ocorrência de eventos extremos de precipitação na região da bacia hidrográfica do Atlântico Sudeste. As análises foram realizadas com dados de precipitação monitorados mensalmente. Os dados foram obtidos do banco de dados da Agência Nacional de Águas (ANA). Foram selecionadas 30 séries pluviométricas espacialmente distribuídas na bacia. O período de estudo foi de 1970-2014.Dentro deste período foram selecionados alguns anos de El Niño, La Niña e anos normais.

Os seguintes parâmetros estatísticos foram utilizados: média, desvio padrão e coeficiente de variação, amplitude, máximo, mínima e anomalias. As anomalias mostraram que em relação às médias climatológicas, ocorreram chuvas mais intensas, devido a presença de eventos ENOS (fase quente), principalmente para os eventos mais intensos.
\end{abstract}

Palavras chave: ENOS, anomalias, bacia hidrográfica do Atlântico Sudeste.

\section{Introdução}

Previsões climáticas que fornecem categorias ou médias sazonais de precipitação total contém informações limitadas, portanto é cada vez mais necessário estabelecer um melhor entendimento das conexões entre o clima e o tempo, tendo em vista que muitos processos de tomada de decisões na sociedade e muitos dos impactos da variabilidade climática são ligados aos eventos do tempo, especialmente eventos extremos de precipitação. Seus casos extremos tem significativo potencial para causar destruição e transtornos, devidos principalmente à relação entre enchentes e deslizamentos de terra. Eventos extremos também podem causar danos à agricultura e a outras atividades. Assim como os episódios de El Niño e La Niña afetam os totais sazonais de precipitação, podem também afetar a frequência de ocorrência de alguns regimes de tempo e assim levando aos eventos extremos.

A Bacia Hidrográfica do Atlântico Sudeste está delimitada pelas coordenadas $17^{\circ} 44^{\prime}$ e $25^{\circ} 28^{\prime}$ de latitude Sul e 39² ' e 4957' de longitude oeste, abrange o sudeste do Brasil (Minas Gerais, Espírito Santo, Rio de Janeiro, São Paulo), $25 \%$ da região Sudeste e uma parte pequena do estado do Paraná, aproximadamente, 5,2 \% (Figura 1). A sua área de abrangência é de $229.972 \mathrm{~km}^{2}$, sendo 2,7 \% do 
território brasileiro. Conhecida nacionalmente pelo elevado contingente populacional e pela importância econômica. Os principais rios são o Paraíba do Sul e o Doce, com respectivamente 1.150 e 853 quilômetros de extensão. Sua população é de 25.644.396 habitantes, 15,1 \% da população do País, sendo 89,7 \% da população vivem em áreas urbanas e especificamente nos litorais do Rio de Janeiro e de São Paulo, esse percentual atinge respectivamente $95,6 \%$ e $97,9 \%$. O Clima é tropical de altitude com temperaturas amenas no verão e tropical úmido nas áreas litorâneas menos elevadas, com chuvas intensas no verão. A precipitação média na região é de $1.352 \mathrm{~mm} / \mathrm{ano}$. Dados retirado da Agência Ncional de Águas.

O objetivo deste trabalho é verificar a dinâmica da variabilidade interanual de precipitação na bacia hidrográfica do Atlântico Sudeste, definindo períodos de anomalias e analisando suas influências em anos de El Niño e La Niña através de análise das precipitações pluviais.

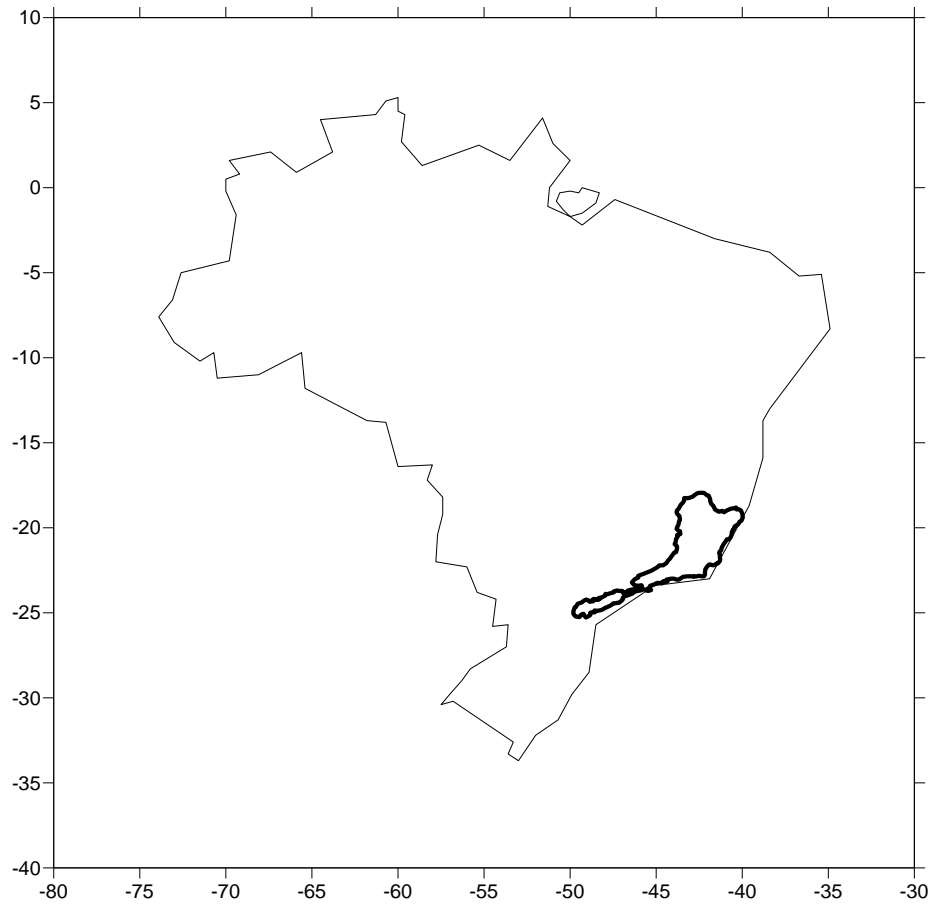

Figura 1 - Localização da área estudada. Autoria Própria.

\section{Material e métodos}

Foram utilizados dados das estações da Agência Nacional de Água (ANA) para analisar dados pluviométricos de um total de 30 séries pluviométricas distribuídas pela bacia no período de 1970-2014. (Figura 2). Uma série de procedimentos estatísticos básicos foram utilizados com o intuito de analisar a 


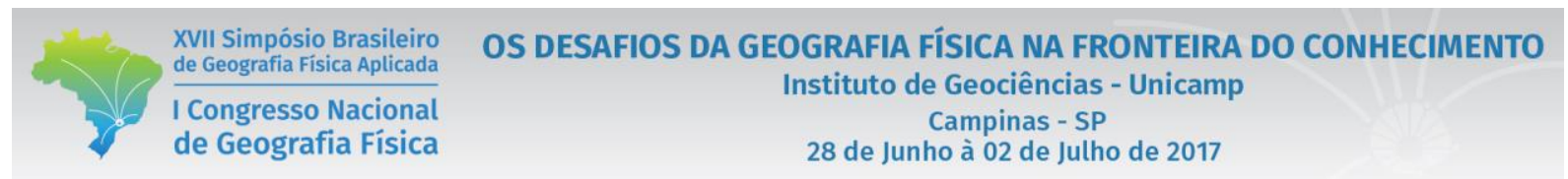

variabilidade pluviométrica da área de estudo, dentro do período. Foram calculados os seguintes parâmetros: média do período, desvio padrão, coeficiente de variação, máximos, mínimos e amplitude.

Com base nesses parâmetros foi possível detectar a variabilidade interanual, baseado nas anomalias para os períodos selecionados. A análise das anomalias no período de 1970-2014 possibilitou classificar alguns anos com eventos El Niño - Oscilação Sul (fase quente) e eventos El Niño - Oscilação Sul (fase fria).

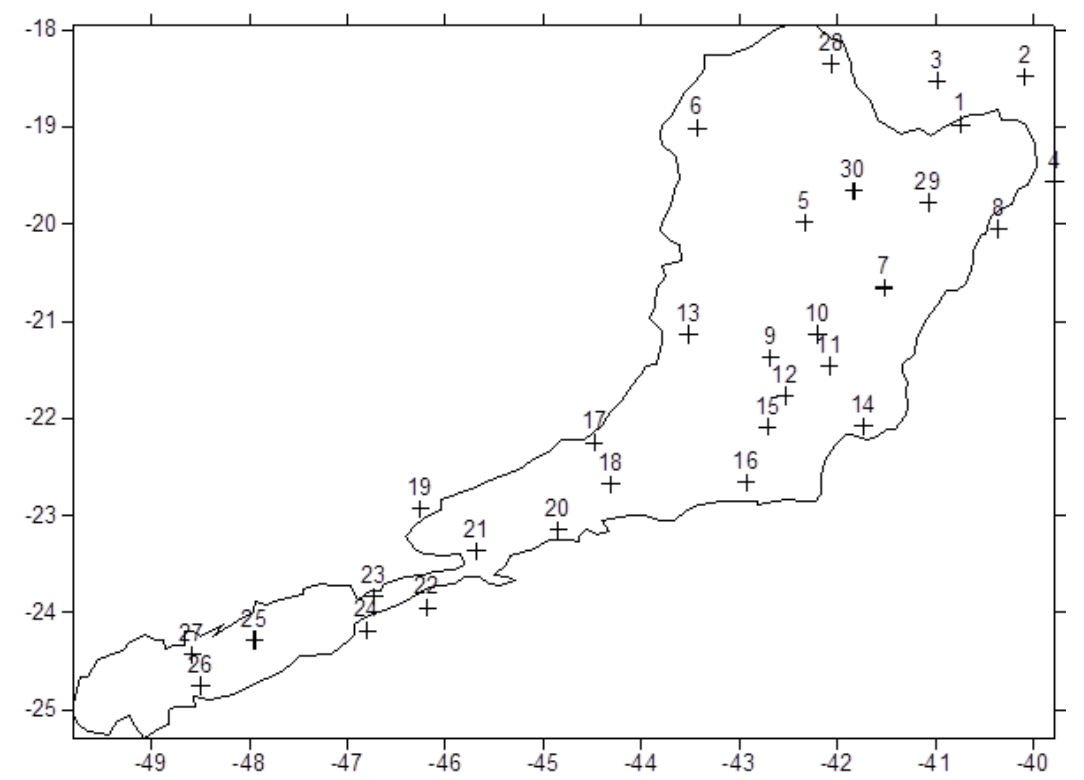

Figura 2 - Localização das séries pluviométricas para o período analisado.

\section{Discussão e resultados}

Analisando-se os mapas observaram-se valores máximos de chuvas maiores no centro leste da bacia, próximo a divisa entre o estado de São Paulo e Rio de Janeiro, com máximas de chuvas de $2.800 \mathrm{~mm}$ no período de 1970-2014. Em relação aos valores mínimos, são localizados ao nordeste da bacia, que apresentam mínimas de $600 \mathrm{~mm}$.

Comparando os mapas de anomalias com o mapa de média climatológica é possível encontrar uma variação de, aproximadamente, $350 \mathrm{~mm}$, na parte mais central da área analisada (Figura 3). As anomalias analisadas foram dos anos de 1976, 1983, 1985, 1990, 1998, 2000 e 2009. Sendo 1976, 1983, 1990, 1998 e 2009 anos de El Niño e 1985 e 2000, anos de La Niña. 


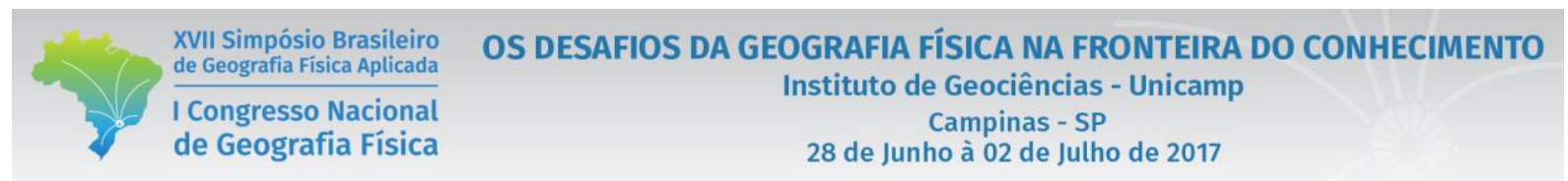

Com base nesta análise nota-se que no ano de 1976 houve anomalias negativas e positivas, apresentando chuvas abaixo da média, com até $-250 \mathrm{~mm}$ a leste e positivas em direção ao sul da bacia com $500 \mathrm{~mm}$ acima da média.

Em 1983 (Figura 4) ocorreram anomalias positivas por toda a bacia hidrográfica, com $850 \mathrm{~mm}$ acima da média a leste e ao norte $300 \mathrm{~mm}$. Uma marcada diferença em relação as anomalias do ano de 1985, que foram negativasem prataicamente toda a bacia. Em 1990 ocorreu anomalia positiva com aumento de chuvas principalmente ao leste da bacia de até 900 mm e em 1998 uma anomalia negativa em toda bacia com chuvas abaixo da média de -100 à $-350 \mathrm{~mm}$, porém em 2000 houve anomalia positiva de até $200 \mathrm{~mm}$ no leste da bacia nas outras áreas estava na média. Em 2009 ocorreu anomalia positiva de até $500 \mathrm{~mm}$ próximo da costa nordeste, enquanto ao leste houve uma anomalia de $200 \mathrm{~mm}$ e no restante da bacia ficou na média.

Os mapas foram traçados através do Surfer V. 8 e utilizando como interpolar o método de krigagem, que é um bom interpolador para dados de precipitação.

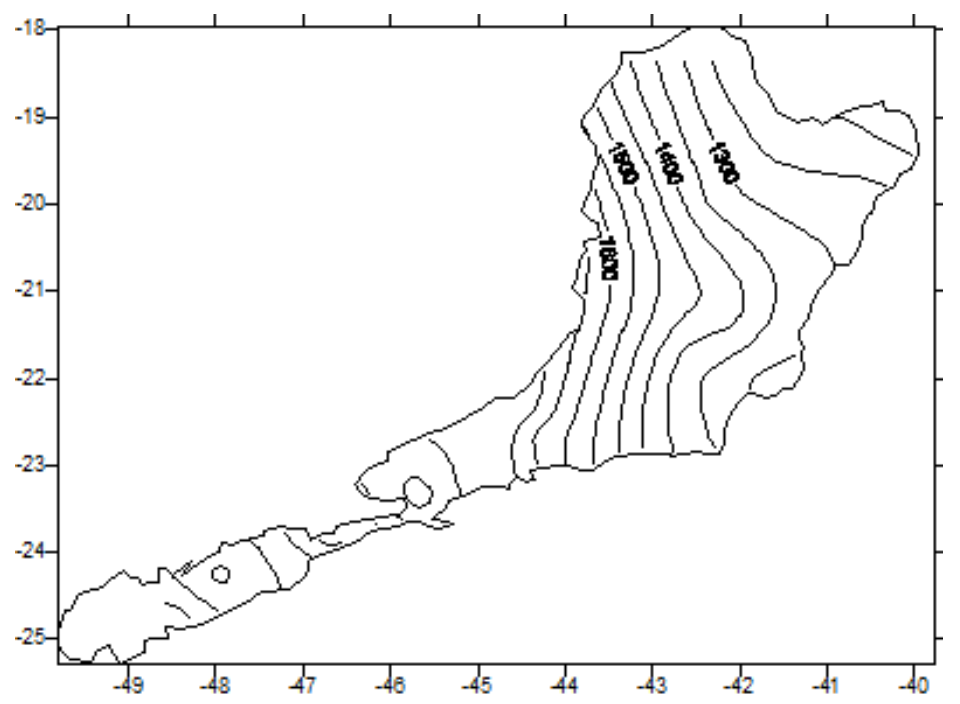

Figura 3 - Média anual da precipitação pluvial $(\mathrm{mm})$ na bacia hidrográfica do Atlântico Sudeste. Período: 1970-2014. Autoria própria. 


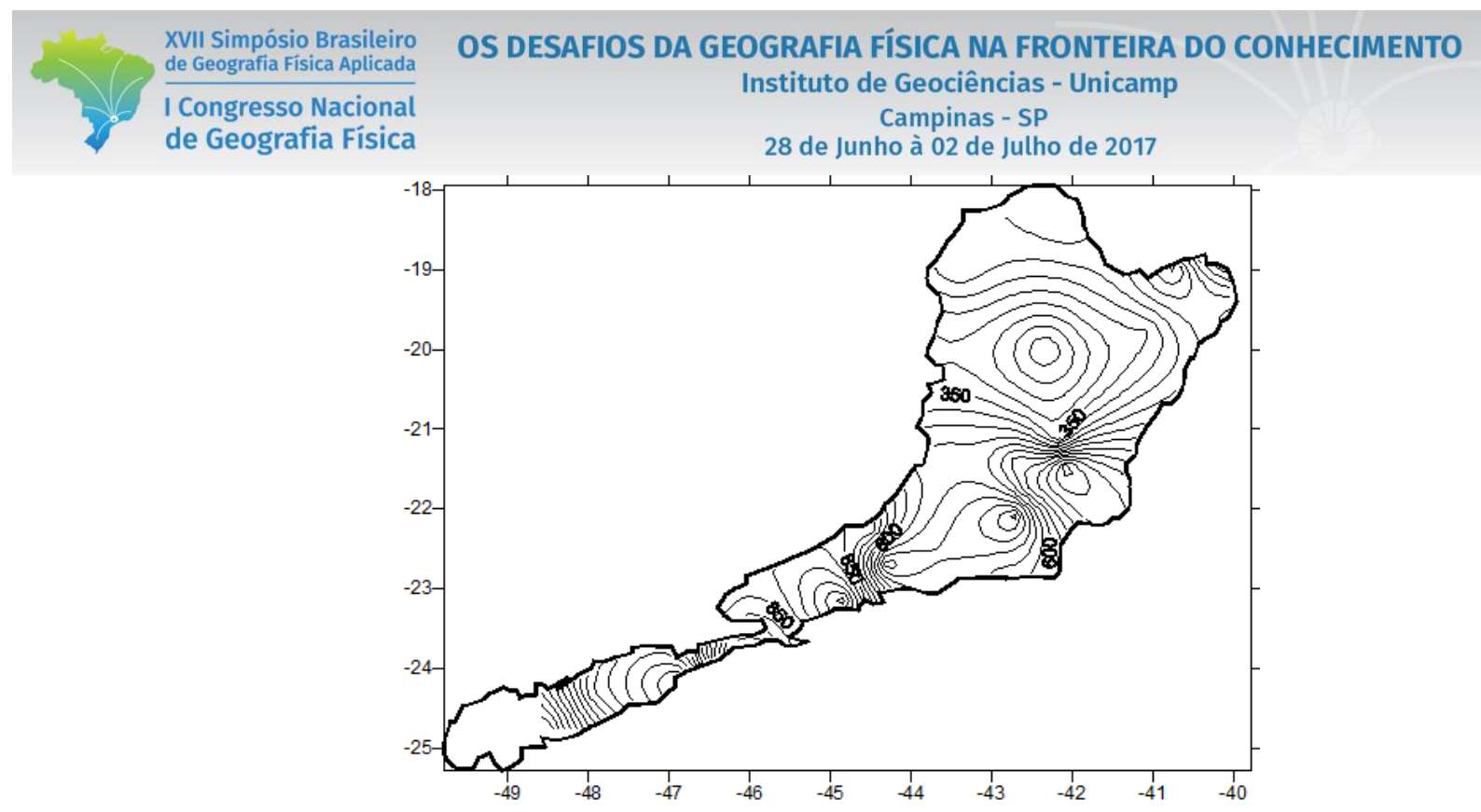

Figura 4 - Anomalia positiva no ano de 1983. Autoria própria.

\section{Conclusão}

As chuvas, nessa unidade de estudo, apresentaram valores médios, para o período, com precipitação pluvial superior a $1.600 \mathrm{~mm}$, ao norte dessa área analisada.

Os máximos de precipitação apresetou valor de $2.800 \mathrm{~mm}$ e valor mínimode $600 \mathrm{~mm}$, o que demostra correr uma acentuada amplitude nessa área.

Observou-se para a região, marcada variabilidade de ano para ano, dentro do período analisado.

Pode-se notar que, para alguns eventos ENOS (fase quente) ou ENOS (fase fria) mais intensos, essa área de estudo tem aumento de chuva nos El Niño mais marcados e diminuição de chuva nas La Niñas de maior intensidade.

\section{Bibliografia}

GRIMM, A.M.; TEDESCHI, R.G. Influência de eventos El Niño e La Niña sobre a freqüência de eventos extremos de precipitação no Brasil. In: CONGRESSO BRASILEIRO DE METEOROLOGIA, 13, 2004, Fortaleza. Anais... Fortaleza: SBMET, 2004. 1 CD-ROM

MANSON, S.J.; GODDARD, L. Probabilistic precipitation anomalies associated with ENSO. Bulletin of the American Meteorological Society, v.82, n.4, p.619-638, 2001.

PHILANDER, S. G H. El Niño, La Niña, and the Southern Oscillation. Intenational Geophysics Series, Academic Press, Inc. 1989.

ANA "Bacia Hidrográfica do Atlântico Sudeste". Disponível em:

<http://www2.ana.gov.br/Paginas/portais/bacias/AtlanticoSudeste.aspx>. Acesso em: Nov/2016 